\title{
Stone Pagamentos: Armadilhas do Crescimento Exponencial
}

\section{Stone Pagamentos: Pitfalls of Exponential Growth}

\author{
José Augusto Lopes Figueiredo \\ Mateus Rodrigues Coimbra \\ Bruno Fernandes \\ Victor Manoel Cunha de Almeida
}

O caso trata dos dilemas de Vabo e Amanda referentes ao desenvolvimento de uma equipe forte, com líderes eficazes, em uma empresa que vinha crescendo exponencialmente. Dada uma nova escala de operação, um novo tamanho de time e os desafios de manter a cultura e continuar crescendo, era necessário reavaliar o papel dos principais líderes, suas interdependências e seus impactos na formação dos líderes do futuro. $O$ caso é recomendado para disciplinas de Liderança, Empreendedorismo e Cultura Organizacional em cursos de pós-graduação stricto e latu senso em Administração de Empresas. Espera-se que, ao final da discussão do caso, os participantes possam: (a) familiarizar-se com a interdependência entre valores, crenças, sonhos, histórico de vida e comportamentos do líder; (b) identificar diferentes estilos de liderança, observando suas características, idiossincrasias e vulnerabilidades; (c) perceber as diferentes necessidades de liderança em cada estágio de desenvolvimento do negócio, bem como as potenciais consequências de cada estilo de liderança no crescimento, pessoas e cultura da empresa; (d) ampliar seu autoconhecimento, fortalecendo suas escolhas, carreira e liderança.

Palavras-chave: Liderança; Empreendedorismo; Estilos de liderança; Cultura organizacional.

This is a case about the dilemmas of Vabo and Amanda regarding the development of a strong team with effective leaders in a company that has been growing exponentially. Given a new scale of operation, a new team size, and the challenges of maintaining the culture and continued grow, it was necessary to re-evaluate the role of key leaders, their interdependencies, and their impacts on shaping the future leaders. The case is recommended for disciplines of Leadership, Entrepreneurship, and Organizational Culture in undergraduate and graduate courses in Business Administration. It is expected that at the end of the discussion the participants will be able to: (a) become familiar with the interdependence

Recebido em: 28/12/2018 Aprovado em: 12/05/2019

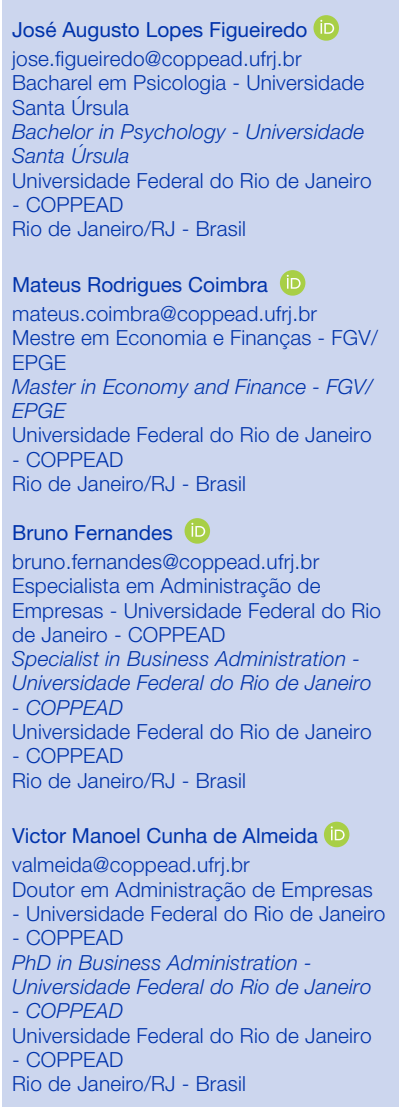


between values, beliefs, dreams, life history, and behaviors of the leader; (b) identify different leadership styles, observing their characteristics, idiosyncrasies, and vulnerabilities; (c) realize the different leadership needs at each stage of business development, as well as the potential consequences of each leadership style on the company's growth, people, and culture; (d) expand their self-knowledge and this way strengthen their choices, career, and leadership.

Keywords: Leadership; Entrepreneurship; Leadership Styles; Organizational Culture.

\section{Introdução}

Já no início da noite de uma terça-feira de maio de 2017, reflexivos depois de um longo dia de muitas explicações, questionamentos e possibilidades, Vabo e Amanda entraram em uma conversa contemplativa sobre o momento em que a Stone Pagamentos vivia e os desafios que o futuro Ihes reservava. Luis Vabo Jr. estava assumindo a direção da área de Gente \& Gestão da empresa e Amanda Luz Sant'Anna era sua antecessora neste papel. Ambos demonstravam um entusiasmo contagiante, fruto do orgulho de fazer parte do sucesso e reputação que a Stone sempre representou. Entretanto, o what's next já gerava neles uma inquietação, comportamento típico de empreendedores, especialmente diante do desafio de liderança e gestão que a expansão acelerada da companhia proporcionava.

A Stone nasceu em meados de 2012, com um capital inicial de 6 milhões de dólares e um time de aproximadamente 40 funcionários. Em cinco anos, já havia se tornado um dos poucos unicórnios ${ }^{1}$ brasileiros. Em meados de 2017, alcançou um valor de mercado acima de 2,0 bilhões de dólares e um time de mais de 3.000 pessoas, quando conquistou o quarto lugar no ranking de adquirentes ${ }^{2}$ do mercado brasileiro, tendo crescido 78\% entre 2016 e 2017.

Nesta passagem de bastão, Amanda não se sentia confortável em transferir a responsabilidade para Vabo, pois ela assumiria um novo papel na Arpex Capital, holding controladora da Stone. Amanda tinha plena consciência que, direta ou in-

1 Unicórnio é a nomenclatura utilizada para denominar startups que atingem valor de mercado acima de 1 bilhão de dólares.

2 O mercado de adquirentes é descrito no Anexo $A$. 
diretamente, seu legado e seu futuro se misturavam naquele contexto. Destemido, meticuloso e com DNA empreendedor, Vabo ouvia atentamente sua interlocutora, já vislumbrando suas ações frente às principais questões que se colocavam: como melhorar o alinhamento da comunicação dos principais líderes, como atrair e contratar em larga escala os melhores talentos e como garantir a integridade cultural vencedora da Stone em meio a tanta diversidade.

\section{Antecedentes}

A semente do nascimento da Stone começa com o encontro de dois de seus principais líderes e fundadores: André Street e Eduardo Pontes.

André começou a trabalhar precocemente aos 13 anos de idade. Filho de médico e com DNA empreendedor, ele iniciou sua trajetória aos 15 anos com a criação de sua primeira empresa, a Paga Fácil, em 1999. Naquela época, o mesmo já se reunia com os amigos de seus pais para tentar angariar recursos para suas empreitadas. Já Eduardo tinha um perfil mais técnico, era considerado um gênio por André, e trabalhou nos bancos Fleming e Santos, nas áreas tecnologia e infraestrutura. Desde muito jovem, Eduardo já demonstrava ser exímio conhecedor dos meandros tecnológicos dos processos bancários.

André e Eduardo se conheceram em 2005 e começaram a empreender em negócios B2B de meios de pagamento. O objetivo era usar a tecnologia para proporcionar alguma disrupção ou para otimizar algum processo relevante neste setor. Investiram suas ideias e energia para realizar este sonho até construírem um gateway de pagamentos para lojas de comércio eletrônico, ou seja, uma solução digital para processar os pagamentos feitos no checkout das compras online.

Entrar em um mercado até então duopolista, com serviços financeiros muito concentrados, caros, com o maior spread do mundo, ineficientes e muito mal servido de tecnologia, era uma oportunidade. De um lado estava a VisaNet (Cielo), que só trabalhava com a bandeira Visa, e do outro estava a Redecard, que só trabalhava com a bandeira Master, o que, segundo André e Eduardo, era muito ruim para os varejistas e empreendedores, pois os deixava sem opções e reféns de altas tarifas para os negócios de e-commerce, que começavam a crescer no Brasil. 
Foi neste embalo que os empreendedores André e Eduardo criaram a Braspag em 2005. Uma startup de tecnologia que, na essência, facilitava as transações dos varejistas, centralizando as conexões com adquirentes e bancos com condições mais seguras e de menor custo. Já ao final de 2008, a Braspag detinha 80\% do mercado de e-commerce no Brasil. Naquele momento, o time Braspag chegava a 40 funcionários, sendo 25 de tecnologia e o restante de atendimento e comercial. Foi neste momento que Amanda se juntou à equipe da Braspag.

Diante de uma proposta tentadora em 2009, André e Eduardo decidiram vender a Braspag para o Grupo Silvio Santos (GSS). André descreveu a sensação de se juntar a uma estrutura mais formal: "Todos os executivos eram bem mais velhos, só eu e o Edu não usávamos terno e participávamos das reuniões de diretoria à medida que nos interessava; tínhamos toda liberdade, à medida que interagíamos, o aprendizado era mútuo. Foi um período muito legal".

Amanda começou a trabalhar na Braspag no início de 2009, atuando na integração, organizando os processos internos e desenvolvendo KPls operacionais, de atendimento e comerciais. Naquele momento, o foco era acelerar o crescimento e levar a Braspag a um outro patamar.

Amanda relata que ao chegar tudo era muito diferente:

Sempre havia trabalhado em empresas by the book, estruturadas, com processos, procedimentos e muito compliance. Para mim, seguir procedimentos e processos era normal, mas para o Edu e o André isso chegava a ser uma ofensa, às vezes, visto o grau de autonomia e praticidade com que atuavam.

Por força contratual, Eduardo e André se tornaram diretores no GSS, cuidando da Braspag e trabalhando em paralelo no banco Panamericano, que também pertencia ao grupo. Apesar de desfrutarem de todo prestígio e respeito, a estrutura tradicional do banco havia começado a tirar a flexibilidade e a bloquear a inovação que os líderes empreendedores valorizavam em uma startup, fazendo com que eles começassem a imaginar o fim do período de retenção contratual para conquistar novamente sua liberdade, o que não impedia que seus estilos de liderança se fizessem presentes durante aquele período.

Amanda lembra o quão peculiar era o estilo da liderança dos dois empreendedores naquela época: 
Minha primeira semana foi surreal! Cheguei e fiquei esperando o Edu, que era meu chefe, passar as diretrizes. Entrei e esperava que ele viesse falar comigo...Fiquei uma semana sem ter nada para fazer! Nem ele e nem ninguém veio falar comigo. Eu imaginava que ele estava ocupado, por isso não tinha tido chance de me orientar. Comecei a conversar com outras pessoas e percebi que não era uma questão de estar muito ocupado. Tomei coragem e fui bater em sua sala: - Olá Edu será que você teria um tempo para... Ele me interrompeu: - Ah legal! Que bom que você veio aqui!

Amanda confessou que naquele momento pensou que estaria entrando em uma furada. Mas logo depois, quando ele começou a explicar o negócio e as oportunidades, ela compreendeu que era um estilo diferente de liderança e que não havia nenhum problema específico com relação a ela. Amanda acrescentou que, naquele mesmo dia, Edu viria a surpreendê-la novamente, levando-a para uma reunião com todos os líderes e algumas pessoas ainda desconhecidas para ela, rasgando o verbo sobre tudo que deveria ser mudado, sem se preocupar com a forma ou com o que as pessoas poderiam sentir ao ficarem expostas.

Fiquei chocada! Eles gritavam, argumentavam agressivamente e defendiam seus pontos de vista parecendo que brigariam de verdade a qualquer momento. Naquele dia, comecei a conhecer o Edu e seu estilo natural e franco de dizer diretamente o que pensa, doa a quem doer, e depois, surpreendentemente, cultivar um relacionamento pessoal, totalmente sem ressentimentos.

Outra perspectiva que Amanda recorda da época da Braspag é a da autonomia e do empowerment que as pessoas tinham. "Era uma autonomia absurda! Nunca alguém dizia faça assim, faça assado...Falava-se o desafio é esse, te vira e faz acontecer..."

Com o escândalo financeiro do banco Panamericano, que veio a público em novembro de 2010, o GSS decidiu vender alguns negócios, dentre eles a Braspag, que acabou sendo vendida para Cielo em 2011 com a ajuda e intermediação de André, que conseguiu desenhar uma venda pelo dobro do valor que haviam pago originalmente para ele e Eduardo.

Sendo liberados pela Cielo de qualquer compromisso de não competição em dezembro de 2011, Eduardo e André rapidamente partiram para fundação da plataforma que viabilizaria seus sonhos, a Arpex, fundada logo no início de 2012. A intenção não era empreender em uma empresa específica como executivos to- 
cando o dia a dia, mas sim criar uma holding que pudesse investir em uma rede de startups. Evidenciando os valores daquele time, eles caracterizaram a Arpex da seguinte forma:

A ArpexCapital é uma holding de investimentos formada por empreendedores jovens, apaixonados e obsessivos por resultados. Nós queremos ser os melhores no que fazemos, por isso queremos gente melhor do que a gente. Atendemos o varejo através de duas frentes principais: meios de pagamento e serviços para e-commerce. Todas as empresas Arpex compartilham o sonho grande de mudar o cenário brasileiro nestes dois setores e estamos trabalhando em cima de grandes desafios. ${ }^{3}$

Os valores da Arpex são descritos no Anexo B.

Com abertura do mercado de adquirentes pelo Banco Central em 2011, conforme descrito no Anexo A, André intensificou as conversas com investidores e órgãos reguladores, visando conseguir a autorização para atuar como adquirente, ou seja, fazer a liquidação financeira das transações através de cartão de crédito e cartão de débito. Enquanto, André viajava o mundo inteiro para vender o projeto, levantar funding e conquistar a credibilidade, Eduardo trabalhava 24 horas por dia para desenvolver o software da plataforma. As licenças foram conquistadas em junho de 2012, ato contínuo nascia a Stone Pagamentos.

\section{Stone Pagamentos Começa a Engatinhar em Tempo Recorde}

A Stone foi forjada com uma proposta diferenciada focada no desenvolvimento dos empreendedores e varejistas. Segundo eles:

Somos muito mais do que uma simples maquininha no balcão. Fazemos você vender mais, gerir melhor e crescer sempre. Nossa missão é transformar a indústria dos meios de pagamentos. Nosso sonho é nos tornar os melhores em atendimento e serviços ao cliente, criando uma experiência de entrega, de venda e de relacionamento bastante diferente, em que sejamos parceiros do lojista. ${ }^{4}$

3 Arpex Capital (2018). Recuperado em 26/12/2018 de br.linkedin.com/company/arpexcapital

4 Stone (2018). Recuperado em 26/12/2018 de www.facebook.com/stonepagamentos 
Frente ao grande desafio de iniciar a operação, Eduardo e outros deixaram seus papeis na Arpex e assumiram diretamente a liderança na Stone. Haviam conseguido a licença, mas ainda faltava a homologação que, basicamente, consistia em provar para as bandeiras de cartões a capacidade de sua plataforma atender e seguir todas as regras.

De acordo com Visa e Master o processo de homologação levaria em média 18 meses, o que drenaria totalmente o folego financeiro da Stone naquele momento, explicou Amanda: "André e Edu assumiram o desafio de fazer em 12 meses e conseguimos concluir em apenas 9 meses". Explicou Amanda com muito orgulho, ressaltando: "Na verdade, tudo aquilo que a gente se propunha, conseguíamos e acontecia muito rápido".

\section{Chegam os Clientes - Foco}

O ano de 2014 foi quando começaram a chegar os primeiros clientes da Stone e junto com eles os problemas associados à nova empresa. Segundo Amanda, foi aquele ano caótico que tudo dava errado: "A gente descobria as coisas e ia montando à medida em que os erros iam aparecendo, apagando os incêndios, mas conseguindo atrair e reter clientes importantes".

Nas palavras de André: "A confusão era enorme, o sistema ainda era experimental, o processamento saía duplicado em alguns clientes. Causamos vários prejuízos, mas no final honramos e indenizamos todos".

Com uma demanda crescente por pessoas e consequente gestão, todo o time alocado na Arpex foi deslocado para a operação da Stone. Alguns negócios da estratégia de serviços de market place da Arpex foram vendidos para que toda atenção fosse dada à Stone.

Amanda montou o time de Recursos Humanos da Stone uma vez que precisavam crescer e tornar a operação escalável. Muito orgulhosa ela explicou: "No início de 2015, tínhamos apenas 70 pessoas e fechamos o ano com mais de 500, ressaltou Amanda".

Fruto de um investimento feito pela Arpex, outro empreendedor importante na história da Stone foi inserido no grupo, Thiago Piau. Ele juntou-se ao time 
liderando todas as operações de $M \& A$ da Arpex neste período. Na perspectiva de Amanda:

Piau era um jovem brilhante, empreendedor e excelente negociador. Ele conseguiu concluir um negócio bastante estratégico da venda da Sievegroup para a B2W, o que permitiu que todos pudessem se concentrar na Stone a partir dali. Entretanto, era um cara muito difícil no trato com pessoas. Vivemos uma época em que ele gritava com as pessoas e seu relacionamento interpessoal ficou complicado. Tivemos conversas muito duras para ele nos escutar. Ele entendeu e desde então, melhorou muito a qualidade de suas interações, tornando-se um dos principais líderes do negócio.

Neste período de transição do caos da startup para scale up, Piau assumiu a direção da área financeira da Stone, consolidando assim o triunvirato da liderança Stone naquele momento: André, um eterno engajador de sonhos focado em vendas, mercado de capitais, regulatório e gente; Eduardo, formalmente como CEO, mas de olho nos desafios tecnológicos, com um olhar sempre à frente dos demais sobre para onde o mercado iria caminhar do ponto de vista de tecnologia e inovações; e Piau, à frente do financeiro e operações.

\section{Criança Grande}

O ano 2015 foi marcado por um crescimento avassalador para Stone. André e Amanda explicaram: "Todas as metas propostas foram batidas, sempre com muita comemoração, fazendo com que fosse um ano sensacional. A gente achava que não dava pra fazer e no final dava, tudo era festa e um tanto caótico".

Na visão de Amanda, 2016 deveria ser o ano de organizar a casa:

Tínhamos muita gente e queríamos de alguma forma preservar a cultura de meritocracia. Não sabíamos mais os nomes das pessoas, tínhamos reestruturações o tempo todo, pessoas com um mês de empresa viravam líderes, pessoas com 19 anos de idade virando líder de área. Comecei a ficar preocupada.

O ano de 2016 foi iniciado com o apoio de uma consultoria externa para fazer um processo de desdobramento de metas, ter processos bem delineados e buscar excelência operacional. Entretanto, o ano esquentou quando surgiu a oportunidade 
de comprar a operação da Elavon, que era o quarto maior player do setor no Brasil, enquanto a Stone era o oitavo.

Elavon era uma operação do Citi e do US Bancorp. Havia chegado ao país em 2011 com a volta do Citi ao segmento de cartões, depois da venda da Redecard. Bem ao estilo de André e Eduardo, em apenas oito semanas entre negociações, due diligence e captação de recursos, a Stone conseguiu fechar o negócio. Piau e Amanda entraram na nova operação para cuidar da seleção dos times e integração. Amanda comentou seu susto: "Parecia que estava tudo resolvido, mas quando eu e Piau chegamos lá e identificamos o grau de hierarquização e diferenças culturais, ficamos assustados com a complexidade da integração".

Durante a transição Eduardo atuava como CEO da Stone; Piau assumiu como CEO da Elavon e Amanda era a responsável por cuidar do processo de gente e integração.

Logo após a integração total dos negócios, Piau retornou a Stone numa estrutura de liderança compartilhada de Co-CEO com Eduardo. Basicamente, Eduardo manteve seu foco em tecnologia e na visão de longo prazo, Piau no financeiro, comercial e parte de operações. André continuou responsável por captações, relação com investidores e inserções nas questões estratégicas e culturais da empresa.

\section{O "Sangue Verde" e a Dinâmica da Liderança Stone}

As bases da identidade Stone estavam bem estruturadas no Rio e São Paulo. Seus valores (ver Figura 1 no Anexo $\mathrm{C}$ ) bem alinhados com o que seus líderes acreditam, o ambiente físico descontraído, despojado e informal, bem estilizado e temático em verde Stone (ver Figura 2 no anexo D). Metas e notas visíveis nas paredes, tudo pronto para a energia jovem fluir em alta intensidade e a empresa acelerar seu crescimento.

Mas o grau de complexidade aumentou muito e o desafio de liderar gente, cultura e comunicação em toda a Stone se tornou enorme, segundo André. Explicando seu estilo e as interações com seus Co-líderes, ele ressalta: 
Acredito muito na co-gestão, mas brigamos muito, somos muito diferentes e ao mesmo tempo muito iguais. Eu e Edu estabelecemos regras de convivência que foram acertadas há mais de 15 anos... Jamais um xinga o outro, jamais um dorme brigado com o outro, temos comprometimento na discordância, não existe "dessa eu estou fora", um conserta os erros do outro. Bola preta é muito raro, mas quando um diz "isso não", respeitamos a bola preta do outro.

André refletiu sobre seu desenvolvimento como líder:

Hoje como conselheiro de uma grande empresa tradicional venho aprendendo a compreender as regras e os riscos das mudanças com um pouco mais de serenidade; aprendendo com a gestão de outras pessoas numa grande empresa. Mas acho que não consigo ter disciplina para fazer reuniões toda segunda às 9:00. Seria difícil trabalhar numa situação em que essa disciplina fosse requerida. Adoro a liberdade.

E complementa comparando com sua origem: "Eu era um bicho meio selvagem, um empreendedor aprendendo muito sozinho, um lixeiro que ia catando coisas pelo caminho, muito voraz nas minhas ideias e as regras sempre me incomodavam, eu transgredia...”.

Ao comparar seu estilo com o Eduardo, ele sorriu:

Eduardo é um disruptor, visionário, meu sócio tecnológico, um par muito complementar, minha alma gêmea, mas se irrita muito com burocracia, mais duro e radical. Coisas que só dono faz e que são radicais e criam caos. Meus defeitos são compensados pela minha cabeça de admirar a inteligência alheia. Tem coisa que só o Eduardo enxerga com muita clareza e antes dos outros. É uma cabeça muito diferente do ser humano normal.

André vem percebendo vários efeitos colaterais não desejáveis na liderança compartilhada, principalmente na comunicação. Em suas palavras: "Às vezes nossos diretos operam a gente, dizem que falaram com um e não falaram com o outro. E a dificuldade é que falamos a mesma coisa, mas de formas diferente e as pessoas não entendem".

Vabo em sua atenta observação comentou: "Muitas vezes o como não é claro. A comunicação não é linear".

Em 2017 introduziram a reunião do Board mensal na qual os principais líderes tratam dos assuntos mais delicados da Stone, procurando alinhar as prioridades.

Segundo André, a responsabilidade de tocar o negócio é do management: 
Queremos formá-los para serem líderes do negócio do futuro. Hoje trabalho na empresa praticamente sem uma função ou cargo, o que hoje eu faço muito é formar líderes. Faço deles meus sócios, espero fidelidade mútua, trabalho muito focado na inteligência emocional e na autoconfiança.

Fruto da crença de seus Founders Partners, o estilo de liderança compartiIhada, em duplas ou trios é replicado, formal ou informalmente em outras funções críticas da organização, por exemplo, em Gente \& Gestão, no Financeiro e na Tesouraria. Segundo Vabo:

Esta liderança compartilhada funciona, pois tem sempre um dono responsável na dupla que tem um acordo muito forte com a gente, que em uma situação de emergência ou impasse tem um líder designado por nós para decidir.

\section{Desafios do Hoje e Amanhã}

Percebendo o silêncio de Vabo, Amanda procurou sintetizar sua confiante perspectiva: - Com nosso jeito agressivo, veloz em fazer as coisas, com uma resiliência absurda do time, adaptado a constantes mudanças, vamos continuar fazendo acontecer, temos capacidade muito rápida de mudar, a gente não hesita. Vamos nessa...

Vabo ponderou: - Num ambiente pequeno onde todos se conhecem muito bem e sabemos os pontos fortes e vulnerabilidades, a gente se cobre, mas e com 3 mil colaboradores? Precisamos ter paciência com o timing, por causa do tamanho. Temos uma comunicação que precisa ser traduzida. Perdemos muita gente boa que não conseguimos engajar ou compreender a diversidade.

Amanda assentiu concordando: - É... Você tem razão. Temos um gap de formação de líderes. Tivemos que trazer uma pessoa para substituir um gerente que, por mais talentoso que fosse, não conseguiria acompanhar a sofisticação e complexidade de nosso tamanho. E além disso, trouxemos outros 5 a 6 diretores de mercado para outras áreas.

Finalizando, aquele dia de muita conversa e reflexão, ambos concordaram que, os três líderes possuem características muito singulares, cada um com sua faceta brilhante, diferentes entre si, apaixonados pelo que fazem, mas pessoas com- 
plexas de se relacionarem e que chegam a um alinhamento através de um processo que, às vezes, é duro e sofrido para aqueles que observam.

Fazendo uma ilustração crítica final, Amanda teceu a seguinte observação sobre o que poderia ter sido diferente:

Na história de uma empresa existem vários momentos. Temos o momento de tirá-la do chão e fazê-la virar algo representativo. Depois disso, existe o momento de garantir que ela continue crescendo e se perpetuando, o que é uma questão de liderança, fazendo um grupo cada vez maior de pessoas seguirem numa determinada direção. Eu acredito que nossa natureza é fantástica em tirar do chão. Eu não sei, e talvez ninguém saiba, se nos sairemos tão bem liderando um negócio deste tamanho. Nunca fizemos isso, vivemos um momento novo numa escala bem maior. É muito fácil virar um barco a remo, mesmo que tenhamos 10 pessoas dentro, basta uma pessoa fazer força que o barco muda de direção. Num transatlântico com 3.000 pessoas as coisas são mais difíceis. Mesmo com 300 pessoas remando numa direção fica muito difícil alterar a rota na hora de pânico.

Imersos nesse questionamento, Amanda e Vabo saíram daquela conversa na noite de maio de 2017 com dúvidas na cabeça. Ambos se questionavam, como fazer para manter a cultura e fomentar uma liderança empreendedora nesse cenário de grande crescimento ou encontrar maior versatilidade de diferentes estilos de liderança? 


\section{ANEXO A}

\section{O MERCADO DE ADQUIRÊNCIA}

Adquirentes são empresas autorizadas a credenciar comerciantes que queiram aceitar cartões de crédito e débito em suas vendas, e a processar pagamentos feitos com estes instrumentos. O processamento destes pagamentos é feito por equipamentos eletrônicos, popularmente conhecidos como "maquininhas", alugados pelas adquirentes aos comerciantes, e que fazem a comunicação com os sistemas das bandeiras de cartões e bancos para que uma transação seja aprovada. No Brasil em 2016, as maiores adquirentes eram controladas por bancos e possuíam cerca de $90 \%$ do mercado. A Cielo, controlada pelo Banco do Brasil e pelo Bradesco, possuía cerca de $50 \%$ do mercado, a Rede, controlada pelo Itaú, possuía cerca de $30 \%$ do mercado, e a Getnet, controlada pelo Santander, possuía cerca de 10\% do mercado.

Subadquirentes também podem credenciar e fornecer "maquininhas" a comerciantes que queiram aceitar cartões de crédito e débito em suas vendas. Entretanto, ao contrário das adquirentes, as subadquirentes não são autorizadas por bandeiras de cartões e bancos a processar diretamente estes pagamentos. Por isso, os equipamentos das subadquirentes fazem a comunicação com os sistemas das adquirentes, que por sua vez processam as transações. No Brasil, algumas das principais subadquirentes são a PagSeguro e o Mercadopago.

Gateways são sistemas que facilitam a aceitação de diversos instrumentos de pagamento nas compras online. Integrados às lojas virtuais, os gateways fazem a comunicação com os sistemas das adquirentes, que por sua vez processam os pagamentos feitos com cartões. O gateway pode também agregar outros serviços, como soluções antifraude e a emissão de boletos. O gateway é transparente para o cliente final, que não precisa sair da página da loja para realizar o pagamento. No Brasil, algumas das principais empresas de gateway são a Braspag e a MundiPagg. 


\section{ANEXO B}

\section{VALORES DA ARPEX CAPITAL}

Espírito de dono: comporte-se como dono, assim você será um deles. Você escreve o seu futuro.

Simplicidade: seja humilde, vá direto ao ponto, reconheça seus erros, conserte rápido, você não precisa fazer o gol "de letra", só o gol. Precisamos ser rápidos para vencer.

Conhecimento: pergunte. Converse, investigue, estude fundo, busque. Só os curiosos descobrem. Não aceite a ignorância.

Obsessão por resultado: nada substitui o santíssimo lucro real. É a única maneira de garantir a perpetuidade. Só os paranóicos vencem.

Meritocracia: só acreditamos em pessoas e organizações que valorizam e recompensam quem gera valor. Dividir o sucesso é fundamental para nossa existência.

Franqueza: franqueza ganha tempo e aproveita melhor o potencial das pessoas. É a maneira mais barata e eficiente para administrar as expectativas e manter a lealdade das pessoas. Pratique a franqueza! É um hábito.

Integridade: nada que seja antiético ou desonesto será tolerado aqui.

Nada se sobrepõe a esse princípio por mais lucro que nos gere. Estamos aqui para fazer o bem. Tire urgente de perto os desonestos, eles se multiplicam rápido.

Sucessão: entranhe a sucessão no seu DNA. Só existe promoção se houver sucessão. Cerque-se de gente melhor do que você. Multiplique-se. Traga gente talentosa porque buscamos ser os melhores e traga gente "do bem" porque queremos ter orgulho do nosso time e prazer de trabalhar aqui.

Ajude os outros: trabalhe em equipe e fomente os relacionamentos. Você só consegue ser grande se tiver um monte de gente colaborando com você.

Paixão: faça o que gosta. Debruce-se com paixão em suas tarefas. A Cia é parte da sua vida e vice-versa. Ame-a ou deixe-a.

Pense grande: dá o mesmo trabalho que pensar pequeno e você só vencerá as barreiras do dia-a-dia se elas forem pequenas perto do seu sonho! 


\section{ANEXO C}

Figura 1 Valores da Stone.

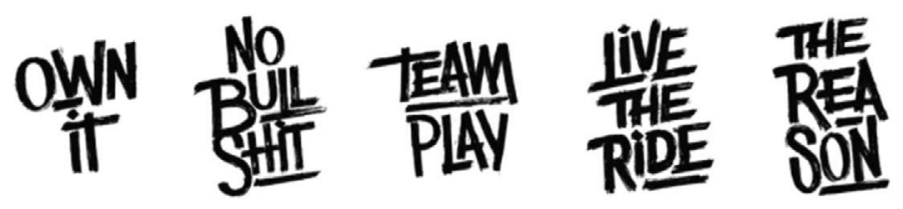

Fonte: Stone.

\section{OS VALORES DA STONE}

- $\quad$ Own it: seja dono de suas escolhas. Não deixe a vida te levar, seja você protagonista do seu destino.

- No bullshit: não deixe que a burocracia atrapalhe seu resultado. Vá e conquiste.

- Teamplay: se você quer ir rápido, vá sozinho. Se quer ir longe, vá em equipe.

- Live the ride: viva a jornada. Aqui, acreditamos em um trabalho com propósito. Vivemos nossas missões.

- The reason: para nós, o cliente não tem sempre razão. O cliente é a razão. 


\section{ANEXO D}

Figura 2 Identidade visual e ambiente da Stone.

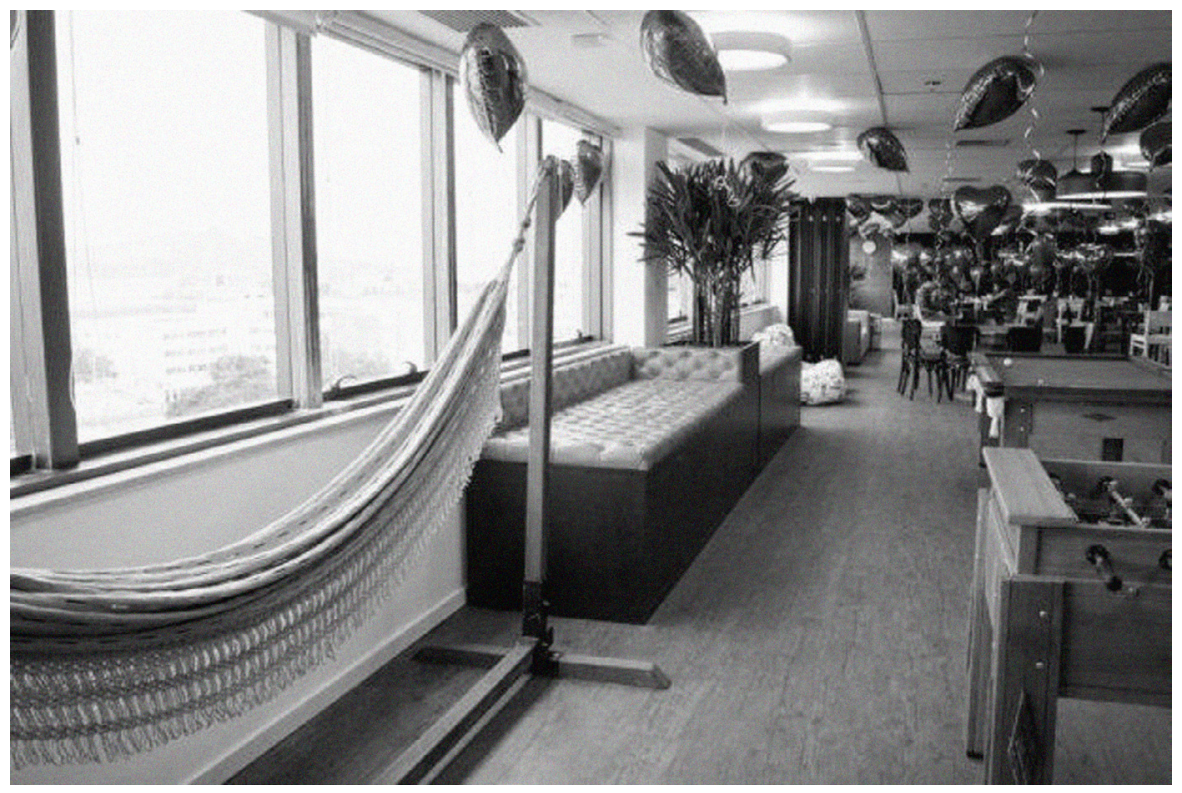

Fonte: Stone. 


\section{Notas de Ensino}

\section{SINOPSE}

O caso trata dos dilemas de Vabo e Amanda referentes ao desenvolvimento de uma equipe forte com líderes eficazes em uma empresa que vinha crescendo exponencialmente. Dada uma nova escala de operação, um novo tamanho de time e os desafios de manter a cultura e continuar crescendo, era necessário reavaliar o papel dos principais líderes, suas interdependências e seus impactos na formação dos líderes do futuro.

\section{OBJETIVOS EDUCACIONAIS}

Este caso foi desenvolvido para estimular a discussão sobre os desafios dos líderes empresariais, encarando a liderança como algo que se aprende e desenvolve, a partir da depuração do autoconhecimento, de escolhas pessoais, conhecimento técnico e princípios éticos. Considerando a área de expertise dos autores, o caso é recomendado para disciplinas de Liderança, Empreendedorismo e Cultura Organizacional em cursos de pós-graduação stricto e latu senso em Administração de Empresas. Entretanto, professores de outras áreas de expertise podem sempre avaliar a aplicação do caso em outras disciplinas e em outros cursos.

Espera-se que, ao final da discussão do caso, os participantes possam: (a) familiarizar-se com a interdependência entre valores, crenças, sonhos, histórico de vida e comportamentos do líder; (b) identificar diferentes estilos de liderança, observando suas características, idiossincrasias e vulnerabilidades; (c) perceber as diferentes necessidades de liderança em cada estágio de desenvolvimento do negócio, bem como as potenciais consequências de cada estilo de liderança no crescimento, pessoas e cultura da empresa; (d) ampliar seu autoconhecimento, fortalecendo suas escolhas, carreira e liderança.

\section{FONTES DE INFORMAÇÃO}

As informações utilizadas para a elaboração deste caso de ensino foram obtidas de fontes primárias e secundárias. Entre as fontes primárias estão entrevistas com André Street, sócio fundador, Amanda Luz Sant'Anna, CFO da holding Arpex e 
anteriormente Diretora de Gente \& Gestão da Stone, Luis Vabo Jr., Diretor Executivo de Gente \& Gestão da Stone e Ricardo De La Vega, responsável pelo departamento de Pessoas, Performance, Remuneração e People Analytics na Stone. As fontes secundárias incluíram websites de empresas do setor de meios de pagamento. Também foram consultados ainda os websites de jornais, revistas e críticos do setor de meios de pagamento, bem como da própria Stone.

\section{PLANO DE ENSINO}

Para a utilização deste caso durante as aulas, leituras prévias são opcionais, dependendo do grau de profundidade desejado. Caso acredite que exista esta necessidade, sugere-se as fontes da Tabela 1 abaixo:

Tabela 1 Leituras prévias opcionais.

\section{Bloco de Conhecimento}

Evolução da pesquisa em Liderança

Abordagem sobre Traços e

Atributos da Liderança

Introdução sobre a pesquisa

em Liderança - Abordagem dos

Traços e Habilidades

Liderança Empreendedora

Crescimento Exponencial

Liderança Transformacional

Autoconhecimento, Valores e

Visão

Autoconhecimento e Liderança

Autentica

\section{Referência}

Capítulo / Páginas

(ANTONAKIS; DAY, 2017)

Cap. 1 pg. 3 - 26

(ANTONAKIS; DAY, 2017)

Cap. 2 pg. $29-55$

Cap 1 pg. 1 - 18

(NORTHOUSE, 2016) Cap 2 pg. $19-41$

Cap 3 pg. 43 - 70

(RENKO, 2017) Cap 15 pg. $381-408$

Cap 3 pg. $48-76$

(ISMAIL; MALONE; Cap 4 pg. 77 - 103

VAN GEEST, 2015) Cap 5 pg. 104-129

Cap 10 pg. $231-252$

(NORTHOUSE, 2016) Cap 8 pg. 161 - 191

Introd pg. 1 - 6

(KOUZES; POSNER, 2012)

Cap 2 pg. $37-60$

Cap 4 pg. 89 - 110

(GEORGE et al., 2016) Artigo completo 
Liderança Empreendedora

Liderança Compartilhada em times empreendedores

Liderança e Narcisismo

Liderança Narcisista e transgressão ética

Liderança Narcisista e excessiva auto confiança
(LEITCH; VOLERY, 2017)
(ZHOU, 2016)
Pg. $153-169$

Pg. $147-156$

(OESTERLE; ELOSGE;

ELOSGE, 2016)

Pg. 1114 - 1123

(DESMET;

HOOGERVORST; VAN Pg. 1034 - 1050

DIJKE, 2015)

(CHEN; CROSSLAND;

LUO, 2015)

Pg. $1513-1535$

Fonte: Autores.

O caso foi elaborado com a intenção da utilização de 20 a 30 minutos para que os alunos discutam o caso em grupos antes da realização da plenária. O tempo total necessário para a sessão plenária pode variar entre 50 e 80 minutos, dependendo da distribuição típica de horários de aula da Instituição de Ensino. A abertura da discussão em plenário deve exigir 10-15 minutos. A análise das questões deve consumir 35-55 minutos. O encerramento da discussão plenária ocupará os 5-10 minutos restantes.

\section{ABERTURA DA DISCUSSÃO DO CASO EM PLENÁRIO}

A abertura da discussão pode ser usada para que os alunos, por meio da observação da trajetória dos personagens e suas vivências, percebam a construção de seus valores e crenças e consequentemente seu comportamento como líderes. A partir da capacidade de compreensão deste processo é que líderes e liderados seriam capazes de flexibilizarem seus estilos e se tornarem mais versáteis em seus papéis. Pois, no fim das contas, segundo Kouzes e Posner (2012), o desenvolvimento da liderança é um desafio de autodesenvolvimento pessoal. O professor pode provocar essa discussão a partir das seguintes perguntas: Como podemos separar nosso lado pessoal do nosso lado profissional? Como podemos ser impetuosos e destemidos no trabalho e relax e cautelosos no lado pessoal? 


\section{QUESTÕES PARA DISCUSSÃO}

A seguir apresentamos um conjunto de questões (discussion questions) que poderiam ser utilizadas para estimular a análise do caso durante a etapa de discussão em plenário:

1. Que desafios se apresentam para Stone?

2. O estilo de liderança dos três principais líderes é coerente com as necessidades atuais da empresa?

3. Quais seriam as potenciais vantagens e desvantagens de uma liderança menos empreendedora e super heroica?

4. Em que medida autoconhecimento passa ser fundamental no desenvolvimento da liderança?

\section{ANÁLISE DO CASO COM SUPORTE DA LITERATURA}

\section{Considerações Teóricas}

Nos últimos cinquenta anos, os CEOs exerceram uma influência cada vez maior sobre as ações e o desempenho de suas empresas (QUIGLEY; HAMBRICK, 2015). Fundadores, especialmente, aqueles em empreendimentos baseados em tecnologia, são frequentemente grandes defensores de seus produtos ou serviços, o que ajuda a fazer a empresa decolar e alcançar o sucesso inicial do produto. No entanto, as habilidades de desenvolvimento de produtos raramente beneficiam esses empreendedores quando se trata de liderar uma equipe de funcionários e motivá-los a trabalhar para a empresa. Muitas vezes, a visão inicial que um fundador oferece àqueles que se juntam à equipe reflete uma devoção fanática à tecnologia, produto ou processos específicos da empresa. Embora esse enfoque possa ser útil para convencer algumas partes interessadas, como financiadores ou outros entusiastas de produto / tecnologia, não é provável que inspire todos os participantes da empresa. Para complicar ainda mais as coisas, os fundadores estão acostumados a estar no controle de tudo, e delegar - até mesmo uma pequena quantidade de controle - pode ser difícil para eles. Não é surpresa, portanto, que muitos fundadores que se destacam na construção de produtos e empresas não sejam bons líderes. Há certamente exceções, como Howard Schultz, da Starbucks, e Fred Smith, da FedEx, que passaram a liderar suas empresas do começo ao grande crescimento. Mas, de maneira geral, liderar pessoas é um desafio para muitos fundadores, e esse 
desafio é um alvo móvel, à medida que as empresas passam pelos estágios iniciais de seus ciclos de vida e experimentam consolidação e crescimento (ANTONAKIS; AUTIO, 2007). Superficialmente, pode parecer que liderar uma organização nova e pequena deve ser mais fácil do que dirigir um grande e antigo operador: em empresas novas e pequenas, as pessoas tendem a permanecer próximas e a saber muito sobre os negócios e todas as partes interessadas, enquanto líderes podem se beneficiam de maneiras informais de fazer as coisas, bem como de sua maior capacidade de usar a observação pessoal, ao invés de sistemas de controle (LEITCH; MCMULLAN; HARRISON, 2013). A liderança empreendedora como um fenômeno contextual está focada no fato de que sua manifestação depende do contexto em que ela ocorre. A pesquisa apresenta abordagens em que líderes de pequenos empreendimentos assumem papéis de liderança para que seus negócios prosperem e cresçam (por exemplo, KANG; SOLOMON; CHOI, 2015; KORYAK et al., 2015; LEITCH; MCMULLAN; HARRISON, 2013), o mesmo ocorrendo em empresas familiares e empresas que atuam de forma empreendedora, independentemente de sua idade e porte (SIMSEK et al., 2015). Líderes empreendedores são tomadores de risco, criativos, apaixonados e visionários. Eles articulam uma visão convincente e diferenciadora para o futuro da empresa e da unidade de negócios e despertam o envolvimento pessoal e o orgulho dos seguidores nessa visão, motivando-os. Além do risco, a criatividade é outra característica que os líderes empreendedores demonstram, sendo ela caracterizada como uma capacidade de gerar ideias perspicazes, expressar pensamentos únicos e fazer descobertas inovadoras. A evolução cronológica e conceitual da Liderança Empreendedora é resumida na Tabela 2.

Tabela 2 Evolução cronológica e conceitual da Liderança Empreendedora.

Fonte Definição

(CUNNINGHAM; Entrepreneurial leadership involves setting clear goals, creatLISCHERON, ing opportunities, empowering people, preserving organiza1991) tional intimacy, and developing a human resource system

(IRELAND; HITT; SIRMON, 2003)
Entrepreneurial leadership entails the ability to influence others to manage resources strategically in order to emphasize both opportunity-seeking and advantage-seeking behaviors 
(COGLISER;

BRIGHAM, 2004)

GUPTA; MACMILLAN; SURIE, 2004)

(THORNBERRY, 2006)

(SURIE; ASH-

LEY, 2008)

(RENKO et al., 2015)

(LEITCH; VOLEY, 2017)

(SKLAVENITI, 2017)
Entrepreneurial leadership must involve generating ideas, structuring ideas, and promoting ideas, in which the generation of ideas is critical in the early stages of an enterprise and the structuring and promotion of ideas in the later stages. So an entrepreneurial leader need not only recognize opportunities, but must also be able to pool the resources needed to reach the potential of that opportunity.

Leadership that creates visionary scenarios that are used to assemble and mobilize a supporting cast of participants who become committed by the vision to the discovery and exploitation of strategic value creation

Leadership requires passion, vision, focus, and the ability to inspire others. Entrepreneurial leadership requires all these, plus a mindset and skill set that helps entrepreneurial leaders identify, develop, and capture new business opportunities Leadership capable of sustaining innovation and adaptation in high velocity and uncertain environments

Entrepreneurial leadership entails as influencing and directing the performance of group members toward the achievement of organizational goals that involve recognizing and exploiting entrepreneurial opportunities.

Entrepreneurs are leaders par excellence who identify opportunities and marshal resources from various stakeholders in order to exploit these opportunities and create value Entrepreneurial leadership is a perpetual and relational process of working together to mobilize business opportunities in organizational contexts in pursuit of entrepreneurial goals

Fonte: Autores.

Ao longo do caso, é possível notar que Vabo busca encontrar um caminho diante das questões de como melhorar o alinhamento da comunicação de seus principais líderes, como atrair e contratar em larga escala os melhores talentos e 
como garantir a integridade cultural vencedora da Stone em meio a tanta diversidade. Além do desafio generalizado do desenvolvimento das pessoas, Vabo precisa encontrar formas de sensibilizar os três principais líderes em flexibilizarem seus estilos de liderança, dando exemplo para toda governança. Este ponto é foco desse caso de ensino e envolve avaliar os prós e contras entre os diferentes estilos (empreendedor, compartilhado e o estilo transformacional) de liderança, e suas interdependências com engajamento, estresse, comunicação e resultados.

\section{Questão 1- Que desafios se apresentam para Stone?}

Antes de discutir os desafios, o professor pode explorar com os alunos como a Stone vinha crescendo e conquistando seu espaço. Recomenda-se que o professor estimule os alunos a discutirem o atual estilo e cultura de liderança a partir das seguintes questões de transição (transition question):

\section{TQ: Quais os problemas que o rápido crescimento pode gerar?}

Comunicação truncada, confusão, excesso de pressão, perda de talentos e líderes com pouca maturidade e inexperiência.

Um líder empreendedor verdadeiramente exitoso não se concentra apenas em inteligência, educação, estilo de vida ou experiência. Um fator principal que parece determinar o sucesso operacional é a capacidade do empreendedor de comunicar efetivamente no ambiente organizacional em desenvolvimento. O rápido crescimento dificulta a comunicação vertical, horizontal, e entre novos funcionários que chegam através das novas contratações. Pessoas com experiência e conhecimentos técnicos importantes para o empreendimento, acabam por não se adaptar a uma comunicação não linear e acabam não conseguindo se engajarem na organização. Pessoas que trabalham para empresas empreendedoras esperam mais direção do chefe, por isso o desenvolvimento e a articulação da visão ganham importância.

TQ: Quais seriam as principais diferenças entre um líder "profissional" e líder dono?

A liderança do CEO é importante para dois efeitos distintos sobre o desempenho organizacional: 
1. Efeito no desempenho organizacional, como resultado da liderança mais distante, ou seja, liderança que ultrapassa os níveis médios de gestão e chega diretamente em níveis inferiores (WALDMAN; YAMMARINO, 1999).

2. Efeito no desempenho organizacional como resultado da maior efetividade da equipe que circunda o CEO.

A escola de liderança do empreendedorismo (CUNNINGHAM; LISCHERON, 1991), como uma abordagem da escola de gestão não técnica, sugere que o empreendedor bem-sucedido também deve ser um líder / mentor efetivo que definirá uma visão e atrairá pessoas para transformar essa visão na realidade.

Gupta, MacMillan e Surie (2004) efetivamente introduziram e definiram o conceito de liderança empreendedora. Esta construção consistiu em duas funções principais do líder empreendedor, enquadrar a visão, absorvendo a incerteza e esclarecendo o caminho para os seguidores, enquanto o segundo consiste em construir compromisso e especificando os limites do comportamento do seguidor. Os times nas empresas de dono apresentaram maior expectativa do que nas empresas com CEOs profissionais, possivelmente pela potência e demanda gerada por uma visão mobilizadora.

O CEO profissional tende a ter desapego dos elementos emocionais que aniquilam o dono ou fundador, levando as decisões para uma instância mais racional. O que se perde pela menor intensidade personificada na figura do dono, os CEOs profissionais ganham no descompromisso com o passado e imparcialidade emotiva, principalmente nas mudanças.

TQ: Quais as vantagens e desvantagens do jeito de liderar através de um triunvirato?

Novos modelos de liderança reconhecem que a efetividade dos sistemas vivos de relacionamentos não depende de líderes individuais e heroicos, mas sim de práticas de liderança incorporadas em um sistema de interdependências em diferentes níveis dentro da organização. Isso deu início a uma era do que muitas vezes se chamou de liderança "pós-heroica" ou compartilhada (PEARCE; CONGER, 2008). A liderança compartilhada foi descrita como um fenômeno de nível de grupo que se afasta da noção tradicional de influência de cima para baixo e argumenta 
que o papel de liderança poderia ser compartilhado pelos membros da equipe simultaneamente ou de forma rotativa, resultando em influência lateral e ascendente (PEARCE; CONGER, 2008).

A liderança compartilhada pode se originar parcialmente dos líderes, díades líderes-seguidores e do contexto e ser transmitida através de mecanismos de traço, cognição e afeto.

Apesar de um reconhecimento generalizado da necessidade de novos modelos de liderança mais relacionais, muitos observam que há uma série de paradoxos e contradições.

Para se envolver em aprendizado e reflexão organizacional dos novos modelos, muitas vezes requer mudanças culturais corporativas profundas e liderança forte para fazer isso acontecer. Para engajar nesse tipo de mudança, as organizações tendem a recorrer a CEOs heróis que, paradoxalmente, são convidados a distribuir autoridade e responsabilidade empresarial. Essas demandas e expectativas conflitantes podem ter um efeito negativo sobre o grupo, não só levando ao desaparecimento dos líderes individuais, mas fazendo com que o próprio grupo duvide dos seus próprios princípios de liderança compartilhada.

As organizações possuem um regime de treinamento e desenvolvimento que está baseado no que alguns chamam de modelo de torneio. Isso encoraja uma tremenda atenção e energia para se diferenciar dos outros, distinguindo suas realizações individuais e o nível de compromisso. O resultado é que empregos e carreiras são organizados em torno de princípios de realização individual e meritocracia.

Vantagens: compartilhar conhecimentos, competências e diferentes perspectivas. Para funcionar bem requer de disciplina na comunicação e gestão.

Desvantagens: processo mais lento, falta de disciplina gera confusão e burocracia. Não alinhamento precisa ser fortalecido por muita comunicação.

\section{Questão 2- O estilo de liderança dos três principais líderes era coerente com as necessidades atuais da empresa?}

Não. Depreende-se do caso que o estilo de liderança em 2017 continua sendo o mesmo utilizado no startup, ou seja, um estilo empreendedor. A liderança empreendedora emergiu como algo distintivo, seja por causa das especificidades contextuais do exercício da liderança principalmente em startups, ou devido as 
constantes mudanças de contexto no qual se encontram todas as organizações e instituições (HARRISON; LEITCH; MCADAM, 2015), e como forma de criar e renovar suas operações, construindo capacidade para competir em novos mercados (NARAYANAN; YANG; ZAHRA, 2009). Os líderes e gestores entendendo que as pressões para aumentar os lucros, não podiam mais ser atendidas pelas reestruturações que marcaram os anos 90 (NARAYANAN; YANG; ZAHRA, 2009) o interesse e pesquisas, sobre o empreendedorismo cresceram. Dunne et al. (2016) encontraram evidências de que mesmo os pequenos líderes empreendedores que são inspiradores, que negociam competitivamente e que lideram organizações eficazes estabelecem ambientes que seriam mais propensos a produzir inovações.

O porte apresentado pela Stone em 2017 sugere que o estilo de liderança deva também contemplar elementos da liderança transformacional.

A abordagem transformacional sobre a liderança vem ocupando o foco das pesquisas desde o início dos anos oitenta, possivelmente levando-a ao status de principal abordagem de pesquisa sobre liderança (NORTHOUSE, 2016). A Liderança transformacional seria um processo que incorpora as lideranças carismática e visionária, e consistindo numa forma de influência que move os seguidores na conquista de mais resultados do que são esperados (NORTHOUSE, 2016). A liderança transformacional possui quatro componentes: carisma (influência idealizada), consideração individualizada, motivação inspiradora e estimulação intelectual.

Os líderes empreendedores considerariam seguidores em termos de sua paixão empreendedora e sua eficácia (RENKO et al., 2015). Já os líderes transformacionais reconheceriam as necessidades e habilidades únicas de seus seguidores e os tratariam como indivíduos, estabelecendo relações individuais, compreendendo e considerando suas habilidades diferenciais de forma individualizada (AVOLIO; BASS, 1995). Parece-nos que o líder transformacional teria a capacidade de tirar o foco de si próprio e buscar escutar o outro. Ao passo que o líder empreendedor demonstraria a paixão por sua criação, e consequentemente por si próprio, podendo ficar mais longe, de genuinamente demonstrar o reconhecimento de seus seguidores.

TQ: Quais os estilos de liderança identificados e quais suas características?

Liderança Empreendedora, Liderança Compartilhada e Liderança Narcisista. Liderança Narcisista 
O narcisismo residiria no coração da liderança. Este olhar teve sua origem na perspectiva psicodinâmica que defendia a ideia de que processos psicológicos, sociais e emocionais entre líderes e seguidores teriam grande impacto na eficiência e qualidade das relações (NORTHOUSE, 2016). Em papéis de liderança, Northouse (2016) enfatizou que o narcisista construtivo tenderia a ser relativamente bem equilibrado e ter vitalidade e autoestima, capacidade de introspecção e empatia. Segundo Northouse (2016), os líderes construtivos inspirariam os outros não apenas a serem melhores no que fazem, mas também a mudar inteiramente o que fazem. Diametralmente opostos os líderes narcisistas reativos ou excessivos, segundo Northouse (2016), seriam focados em questões de poder, status, prestígio e superioridade, operando na sua própria realidade, sem medidas de controle ou testes de realidade.

As características que se procuram num líder tais como excesso de confiança, extroversão, dominância, elevada autoestima e charme, os narcisistas possuem em abundância. Segundo Campbell et al. (2011), talvez não existisse certo ou errado na análise do narcisismo, mas o fenômeno teria sido usado para explicar o comportamento de líderes empresariais e principalmente seus comportamentos destrutivos no topo da organização.

Muitos dos líderes mundiais e CEOs foram percebidos com características narcisistas (DELUGA, 1997; GLADWELL, 2002; MACCOBY, 2004). A lista de renomados CEOs que poderiam se encaixar no perfil narcisista pela imprensa popular, conta com nomes tais como, Jack Welch, Michael Eisner, Larry Ellison e Bob Nardelli (GLADWELL, 2002; MACCOBY, 2004).

Chatterjee e Pollock (2016) apresentam em sua recente pesquisa a existência de duas necessidades poderosas e conflitantes nas interações sociais dos CEOs narcisistas: (1) a necessidade de aclamação e aprovação social e (2) a necessidade de dominar e controlar os outros. Argumentam que os CEOs narcisistas atendem a seus desejos conflitantes de aclamação e dominação através da maneira como estruturam e gerenciam seus mundos profissionais.

\section{Questão 3- Quais seriam as potenciais vantagens e desvantagens de uma lide-} rança empreendedora?

A liderança empreendedora é frequentemente percebida como um elemento chave para o desenvolvimento de um novo empreendimento e seria considerada a 
força que sustenta o impulso para a mudança (DAILY, 2002; LEITCH; MCMULLAN; HARRISON, 2013).

A variedade de perspectivas adotadas e as definições oferecidas levaram alguns estudiosos a afirmar que a liderança empreendedora permaneceria teórica e careceria de clareza de definição e de ferramentas apropriadas para avaliar suas características e comportamentos (LEITCH; MCMULLAN; HARRISON, 2013). Narayanan, Yang e Zahra (2009) reconheceram que o empreendedorismo também poderia existir em grandes organizações, por exemplo, em empresas de capital aberto, pequenas e médias, bem como, em empresas familiares, através de um processo pelo qual um indivíduo ou um grupo de indivíduos instigariam a renovação organizacional ou inovação dentro dessa organização.

Vantagens: capacidade de mobilização e engajamento, energia elevada, acelera mudanças e facilita inovação.

Desvantagens: identidade da empresa dependente da identidade do líder (BARRETT, 1998), excessivamente focada nas necessidades e valores do líder e não dos seguidores. Comunicação não linear e emocional, em organizações de grande porte precisa ser bem alinhada. Não foca nos indivíduos.

TQ: Se vocês assumissem o papel de conselheiro independente de administração na Stone qual a recomendação você daria para os líderes super-heróis?

O objetivo desta questão é forçar o aluno a trocar de perspectiva em sua análise. Sentar na cadeira do conselho e ter uma postura crítica sobre o grau de centralização que um líder super-herói demonstra, bem como os riscos associados: centralização, trabalho em excesso, risco de sucessão etc.

\section{Questão 4- Em que medida autoconhecimento passa ser fundamental no de-} senvolvimento da liderança?

Autoconhecimento passa a ser vital para compreensão das características (valores, competências, vulnerabilidades etc) dominantes do líder. Todo mundo tem a capacidade de inspirar e de fazer os outros crescerem. Primeiro, porém, a pessoa precisa se dedicar ao próprio crescimento e desenvolvimento como líder (GEORGE et al., 2016). A ressignificação da trajetória de vida é uma perspectiva extremamente poderosa no desenvolvimento da consciência de liderança. 
A cultura de uma organização é um reflexo da consciência de seus líderes (BARRETT, 1998), portanto a transformação cultural começa com a transformação pessoal de seus líderes.

Numa pesquisa George et al. (2016) entrevistaram 125 dirigentes para saber como haviam adquirido a capacidade de liderar. Essas entrevistas constituíram o maior estudo em profundidade sobre desenvolvimento de liderança já realizado. Os entrevistados falaram aberta e honestamente sobre como atingiram seu potencial e expuseram com franqueza histórias de vida, lutas pessoais, fracassos e triunfos. Ao analisar 3 mil páginas de transcrições a equipe constatou, pasma, que esses indivíduos não apontavam nenhum estilo, talento, traço ou característica universal na raiz de seu sucesso. A liderança emergia, antes, da história de vida. De modo consciente e inconsciente, essas pessoas estavam constantemente testando a si mesmas por meio de experiências na vida real e reformulando sua história de vida para entender quem, no fundo, eram.

A maior lição é que a pessoa deve formular sua história de vida de modo a se enxergar não como observadora passiva da própria trajetória, mas como alguém capaz de adquirir consciência de si mesmo a partir da experiência. O líder autêntico usa essa consciência para pôr em prática seus valores e princípios, às vezes com alto risco para si mesmo. Tal líder equilibra sua motivação para agir com base nesses valores internos, e não só pelo desejo de reconhecimento ou recompensa externos.

\section{ENCERRAMENTO DA DISCUSSÃO DO CASO}

Para encerrar, o professor pode provocar uma reflexão sobre os estilos de liderança que os próprios participantes gostariam de desenvolver. A provocação pode ser feita a partir da seguinte pergunta: dado tudo que foi discutido, que estilos de liderança vocês gostariam de desenvolver?

É possível que o debate sobre os estilos e a reflexão implícita sobre o impacto destes estilos nas organizações onde os participantes atuam se estendam para além da sala de aula.

\section{O QUE ACONTECEU}

Consciente de seus desafios, a direção de Gente \& Gestão adotou uma série de ações para conseguir atender o ritmo de crescimento da organização. Estrutu- 
rou uma academia de liderança para formação de seu pipeline de líderes Stone, redesenhou alguns processos de onboarding dos novos executivos e introduziu o processo de coaching externo para os principais líderes da organização. Em outubro de 2018 a Stone realizou com sucesso IPO na bolsa de NY, o que fez com que as práticas de gestão e liderança, além de compliance e governança, passassem a ser ainda mais valorizadas.

\section{Referências}

ANTONAKIS, J.; AUTIO, E. Entrepreneurship and leadership. In: BAUM, J. R.; FRESE, M.; BARON, R. A. The psychology of entrepreneurship. Mahwah: Lawrence Erlbaum Associates, 2007. p. 189-207.

ANTONAKIS, J.; DAY, D. V. The nature of leadership. Thousand Oaks: Sage, 2017.

AVOLIO, B. J.; BASS, B. M. Individual consideration viewed at multiple levels of analysis: a multi-level framework for examining the diffusion of transformational leadership. The Leadership Quarterly, v. 6, n. 2, p. 199-218, 1995. DOI: 10.1016/1048-9843(95)90035-7.

BARRETT, R. Liberating the corporate soul: building a visionary organization. Woburn: Butterworth-Heinemann, 1998.

CAMPBELL, W. K. et al. Narcissism in organizational contexts. Human Resource Management Review, v. 21, n. 4, p. 268-284, 2011. DOI: 10.1016/j.hrmr.2010.10.007.

CHATTERJEE, A.; POLLOCK, T. Master of puppets: how narcissistic CEOs construct their professional worlds. Academy of Management Review, v. 42, n. 4, p. 703-725, 2016. DOI: 10.5465/amr.2015.0224.

CHEN, G.; CROSSLAND, C.; LUO, S. Making the same mistake all over again: CEO overconfidence and corporate resistance to corrective feedback. Strategic Management Journal, v. 36, n. 10, p. 1513-1535, 2015. DOI: $10.1002 / \mathrm{smj} .2291$.

COGLISER, C. C.; BRIGHAM, K. H. The intersection of leadership and entrepreneurship: mutual lessons to be learned. Leadership Quarterly, v. 15, n. 6, p. 771-799, 2004. DOI: 10.1016/j.leaqua.2004.09.004. CUNNINGHAM, J. B.; LISCHERON, J. Defining entrepreneurship. Journal of Small Business Management, v. 29, n. 1, p. 45-61, 1991.

DAILY, C. M. Governance and strategic leadership in entrepreneurial firms. Journal of Management, v. 28, n. 3, p. 387-412, 2002. DOI: 10.1177/014920630202800307.

DELUGA, R. J. Relationship among American presidential charismatic leadership, narcissism, and rated performance. The Leadership Quarterly, v. 8, n. 1, p. 49-65, 1997. DOI: 10.1016/S1048-9843(97)90030-8. DESMET, P. T. M.; HOOGERVORST, N.; VAN DIJKE, M. Prophets vs. profits: how market competition influences leaders' disciplining behavior towards ethical transgressions. Leadership Quarterly, v. 26, n. 6, p. 1034-1050, 2015. DOI: 10.1016/j.leaqua.2015.07.004.

DUNNE, T. C. et al. The impact of leadership on small business innovativeness. Journal of Business Research, v. 69, n. 11, p. 4876-4881, 2016. DOI: 10.1016/j.jbusres.2016.04.046. 
GEORGE, B. et al. O poder da liderança autêntica. Harvard Business Review, nov. 2016.

GLADWELL, M. The talent myth. The New Yorker, 14 jul. 2002.

GUPTA, V.; MACMILLAN, I. C.; SURIE, G. Entrepreneurial leadership: developing and measuring a cross-cultural construct. Journal of Business Venturing, v. 19, n. 2, p. 241-260, 2004. DOI: 10.1016/S08839026(03)00040-5

HARRISON, R.; LEITCH, C.; MCADAM, M. Breaking glass: toward a gendered analysis of entrepreneurial leadership. Journal of Small Business Management, v. 53, n. 3, p. 693-713, 2015. DOI: 10.1111/ jsbm.12180.

IRELAND, R. D.; HITT, M. A.; SIRMON, D. G. A model of strategic entrepreneurship: the construct and its dimensions. Journal of Management, v. 29, n. 6, p. 963-989, 2003. DOI: 10.1016/S01492063(03)00086-2.

ISMAIL, S.; MALONE, M. S.; VAN GEEST, Y. Organizações Exponenciais. São Paulo: HSM, 2015.

KANG, J. H.; SOLOMON, G. T.; CHOI, D. Y. CEOs' leadership styles and managers' innovative behaviour: investigation of intervening effects in an entrepreneurial context. Journal of Management Studies, v. 52, n. 4, p. 531-554, 2015. DOI: 10.1111/joms.12125.

KORYAK, O. et al. Entrepreneurial leadership, capabilities and firm growth. International Small Business Journal, v. 33, n. 1, p. 89-105, 2015. DOI: 10.1177/0266242614558315.

KOUZES, J. M.; POSNER, B. Z. O desafio da liderança. Rio de Janeiro: Elsevier, 2012.

LEITCH, C. M.; MCMULLAN, C.; HARRISON, R. T. The development of entrepreneurial leadership: the role of human, social and institutional capital. British Journal of Management, v. 24, n. 3, p. 347-366, 2013. DOI: 10.1111/j.1467-8551.2011.00808.x.

LEITCH, C. M.; VOLERY, T. Entrepreneurial leadership: insights and directions. International Small Business Journal, v. 35, n. 2, p. 147-156, 2017. DOI: 10.1177/0266242616681397.

MACCOBY, M. Narcissitic leaders: the incredible pros, the inevitable cons. Harvard Business Review, jan. 2004.

NARAYANAN, V. K.; YANG, Y.; ZAHRA, S. A. Corporate venturing and value creation: a review and proposed framework. Research Policy, v. 38, n. 1, p. 58-76, 2009. DOI: 10.1016/j.respol.2008.08.015.

NORTHOUSE, P. G. Leadership: Theory and practice. Michigan: Sage, 2016.

OESTERLE, M. J.; ELOSGE, C.; ELOSGE, L. Me, myself and I: the role of CEO narcissism in internationalization decisions. International Business Review, v. 25, n. 5, p. 1114-1123, 2016. DOI: 10.1016/j. ibusrev.2016.02.001.

PEARCE, C. L.; CONGER, J. A.; LOCKE, E. A. Shared leadership theory. Leadership Quarterly, v. 19, n. 5, p. 622-628, 2008. DOI: 10.1016/j.leaqua.2008.07.005.

QUIGLEY, T. J.; HAMBRICK, D. C. Has the "CEO effect" increased in recent decades? A new explanation for the great rise in America's attention to corporate leaders. Strategic Management Journal, v. 36, n. 6, p. 821-830, 2015. DOI: 10.1002/smj.2258.

RENKO, M. Entrepreneurial leadership. In: ANTONAKIS, J.; DAY, D. V. (Ed.) The nature of leadership. Thousand Oaks: Sage, 2017.

RENKO, M. et al. Understanding and measuring entrepreneurial leadership style. Journal of Small Business Management, v. 53, n. 1, p. 54-74, 2015. DOI: 10.1111/jsbm.12086. 
SIMSEK, Z. et al. Strategic leadership and leaders in entrepreneurial contexts: a nexus for innovation and impact missed? Journal of Management Studies, v. 52, n. 4, p. 463-478, 2015. DOI: 10.1111/joms.12134. SKLAVENITI, C. Processes of entrepreneurial leadership: co-acting creativity and direction in the emergence of new SME ventures. International Small Business Journal, v. 35, n. 2, p. 197-213, 2017. DOI: $10.1177 / 0266242616673420$.

SURIE, G.; ASHLEY, A. Integrating pragmatism and ethics in entrepreneurial leadership for sustainable value creation. Journal of Business Ethics, v. 81, n. 1, p. 235-246, 2008. DOI: 10.1007/s10551-0079491-4.

THORNBERRY, N. Lead like an entrepreneur: keeping the entrepreneurial spirit alive within the corporation. Fairfield: McGraw Hill, 2006.

WALDMAN, D. A.; YAMMARINO, F. J. CEO charismatic leadership: levels-of- management and levels-of-analysis effects. Academy of Management Review, v. 24, n. 2, p. 266-285, 1999. DOI: 10.5465/ AMR.1999.1893936.

ZHOU, W. When does shared leadership matter in entrepreneurial teams: the role of personality composition. International Entrepreneurship and Management Journal, v. 12, n. 1, p. 153-169, 2016. DOI: 10.1007/s11365-014-0334-3. 